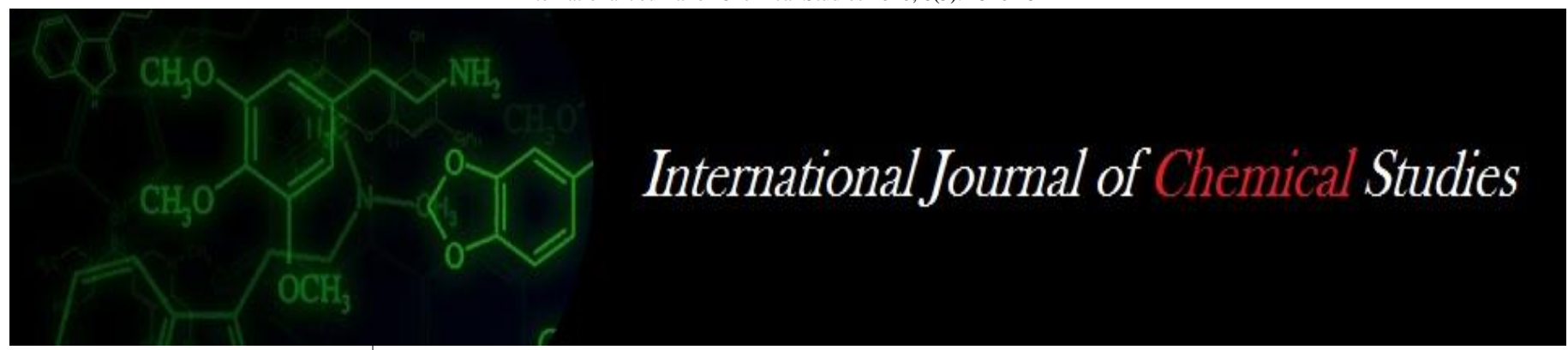

P-ISSN: 2349-8528

E-ISSN: 2321-4902

www.chemijournal.com

IJCS 2020; 8(5): 1520-1522

(C) 2020 IJCS

Received: 21-07-2020

Accepted: 28-08-2020

\section{Rama Maurya}

College of Community and

Applied Science, Maharana

Partap University of Agriculture

and Technology Udaipur

Rajasthan, India

\section{Archana Chakraborty}

Collage of Home Science, M.M.V.

BHU, Varanasi, Uttar Pradesh,

India

Sandeep K Mauriya

Assistant Professor, Narayan

Institute of Agricultural

Sciences, Gopal Narayan Singh,

University, Jamuhar, Sasaram,

Rohtas, Bihar, India

\section{Renu Mogra}

College of Community and

Applied Science, Maharana

Partap University of Agriculture

and Technology Udaipur

Rajasthan, India
Corresponding Author:

Rama Maurya

College of Community and

Applied Science, Maharana

Partap University of Agriculture

and Technology Udaipur

Rajasthan, India

\section{Product development with the enrichment of fenugreek seeds for celiac disease (CD)}

\author{
Rama Maurya, Archana Chakraborty, Sandeep K Mauriya and Renu \\ Mogra
}

DOI: https://doi.org/10.22271/chemi.2020.v8.i5u.10515

\begin{abstract}
Celiac disease $(C D)$ is an autoimmune disorder in which the inability to digest cereals protein gluten. Patients may suffer from malabsorption diarrhea, abdominal pain, anemia, osteoporosis, and failure to thrive. Either CD is a genetic disorder but diet could play an important role to control from pathogenic symptoms. The susceptible person's slow growth rate, it also affects the productive life and also produces low immunity. The present study aimed to develop a gluten-free diet for celiac disease and analyses the acceptability by hedonic rating scale at 9 point scale, like extremely to dislike extremely. The study has done with the enrichment of fenugreek seeds to the preparation of fermented food Idli for celiac patients. Idli batter is prepared by soaking raw milled rice and decorticated black gram for 4 hour at $30 \pm 1{ }^{\circ} \mathrm{C}$ in water. The soaked mass was ground using a mixer grinder with adequate amount of water. Fenugreek seeds contain protein, with the mixing of other pulses the quality of proteins enhances. Fenugreek seeds also contain mucilaginous fiber which is good for health promotion growth, improves immunity.
\end{abstract}

Keywords: Celiac disease (CD), genetic disorder, malabsorption, gluten, mucilaginous fiber, immunity

\section{Introduction}

This research study focuses on the contemporary approaches that are used to increase nutrient and bioactive compound contents of gluten-free Idli (GFI) and highlights the use of nutrientdense alternative raw materials, nutritional and functional ingredients, and their combinations. In this study evaluation of the sensory and nutritional properties was done. The gluten-free products can be fortified with health-promoting active ingredients to produce based functional food. The viability of the active ingredients such as probiotics in the final products should be sufficient to confer beneficial influence on consumer health. However, for the fermenting process, it is there are certain other nutrients and vitamins are also activated. This research aims to focus on recent advances and challenges in the development of fermented products. Traditionally, Idli preparation is as follows: i) rice and black gram were soaked separately, ii) after draining the water, rice and black gram were grind separately with occasional addition of water during grinding process, iii) the rice and black gram batters were then mixed together with addition of a little salt, iv) the mixture was allowed to ferment overnight at room temperature, v) the fermented batter was dispensed in special Idli pans and allowed for steaming for 5-8 min (Balasubramanium et al., 2006) ${ }^{[5]}$. There are many changes, reported during fermentation include an increase in free sugar, non-protein nitrogen (Desikachar et al., 1962) ${ }^{[6]}$, free nicotinic acid (Rajalakshmi et al., 1964) ${ }^{[7]}$, methionine and choline in Idli (Doughty, 1964) and a breakdown of phytate occurs in bread dough (Davidson et al., 1963) and of trypsin inhibitors in certain fermented legume preparations (Aykroyd, 1963) ${ }^{[9]}$. These changes during fermentation are highly significant for nutritional point of view. An increase in methionine, a limiting essential amino acid in legumes, greatly improves protein value. The vitamins content of Idli batter per $100 \mathrm{~g}$ are $0.59 \mathrm{mg}$ riboflavin, $0.59 \mathrm{mg}$ thiamine and $0.76 \mathrm{mg}$ folic acid.

\section{Green gram}

Moisture 10.1, Energy- 348, CHO-59.9, Protein-24.5 Fat-1.2 Minerals- 3.5, Fibre-0.8, Calcium-75, Iron-8.5, Thiamin- 0.72, Riboflavin-0.15 Niacin- 2.4 Vit- A 49 (Sumati et al., 2007) ${ }^{[4]}$. 


\section{Black gram}

Moisture 10.9, Energy- 347, CHO- 59.6, Protein- 24.0, Fat1.4 Minerals- 3.2, Fibre-0.9,Calcium-154, Iron-9.1, Thiamin0.42, Riboflavin- 0.37, Niacin- 2.0, Vit.A - 38 (Sumati et al., 2007) ${ }^{[4]}$.

\section{Raw, milled Rice}

Moisture- 13.7, Energy- 345, CHO-78.2, Protein-6.8, Fat- 0.5 Minerals-0.6, Fibre- 0.2, Calcium- 10, Iron- 3.1, Thiamin 0.06, Riboflavin- 0.06, Niacin- 1.9 (Sumati et al., 2007) ${ }^{[4]}$.

\section{Fenugreek seeds}

It is used as an appetizer, a tonic and an aphrodisiac, and it is included in many foods and beverages. Fenugreek has a long history of dubious indications, including fevers, colic, flatulence, dyspepsia, dysentery, cough, tuberculosis, edema, rickets, leg ulcers, gout, diabetes and baldness. The chemical trigonelline is converted into niacin when the seed is roasted. The seeds also provide a mucilaginous fiber content that may benefit the bowel. Of more current interest is the evidence that fenugreek has a minor hypoglycemic effect, thus suggesting it may, in fact, help with diabetes. There is also some evidence that it can reduce hypercholesterolemia in animals (Bentley et al. 1880) ${ }^{[3]}$. Fenugreek seeds provide 1,350 kilojoules $(323 \mathrm{kcal})$ of food energy and contain $9 \%$ water, $58 \%$ carbohydrates, $23 \%$ protein and $6 \%$ fat, with calcium at $40 \%$ of the Daily Value (USFDA, 2017).

\section{Materials and Methods \\ Procurement of raw materials}

The raw materials selected for this study were raw, milled rice (Oryza sativa), decorticated black gram (Vigna mungo) and decorticated green gram (Vigna radiate), fenugreek seeds (Trigonella foenum-graecum) and salt that were procured from a local market.

Standardization of recipe: rice and decorticated black gram taken 100:40 for the control sample, the second sample contains $5 \%$, the third sample $10 \%$ and the fourth one was $15 \%$ level standardization of raw materials with fenugreek seeds.

- Preparation of Idli product: raw materials taken in given proportions, clean, wash and soak for overnight. Drains the water from it grind in mixer grinder make a smooth Idli batter. Add salt and mix properly then put it on Idli stand for steaming for 8- 12 minutes.

- Sensory evaluation of Idli by hedonic rating scale and organoleptic taste: Admixture of $15 \%$ of fenugreek seeds and $20 \%$ green gram dal was more acceptable.

\section{Detail of treatments and symbols used in the experiment}

Table 1.

\begin{tabular}{|c|c|}
\hline Treatment standardization of Idli mix & Symbol \\
\hline $100: 40$ & $\mathrm{~T}_{0}$ \\
\hline $100: 20: 10: 5$ & $\mathrm{~T}_{1}$ \\
\hline $100: 20: 15: 10$ & $\mathrm{~T}_{2}$ \\
\hline $100: 20: 20: 15$ & $\mathrm{~T}_{3}$ \\
\hline
\end{tabular}

\section{- Statistical analysis}

Table:-Mean \pm SD of characteristics of the sample (Sample T0, T1, T2, T3)
Table 2.

\begin{tabular}{|c|c|c|c|c|}
\hline & $\mathbf{T}_{\mathbf{0}}$ & $\mathbf{T}_{\mathbf{1}}$ & $\mathbf{T}_{\mathbf{2}}$ & $\mathbf{T}_{\mathbf{3}}$ \\
\hline Characteristics & Mean \pm SD & Mean $\pm \mathrm{SD}$ & Mean $\pm \mathrm{SD}$ & Mean $\pm \mathrm{SD}$ \\
\hline Colour & $2.6 \pm 0.49$ & $5.2 \pm 0.46$ & $3.0 \pm 0.50$ & $3.2 \pm 0.68$ \\
\hline Flavor & $2.8 \pm 0.57$ & $3.2 \pm 0.78$ & $3.2 \pm 0.78$ & $3.2 \pm 0.79$ \\
\hline Texture & $2.8 \pm 042$ & $2.9 \pm 0.72$ & $3.1 \pm 0.64$ & $2.8 \pm 0.68$ \\
\hline Taste & $2.8 \pm 0.52$ & $3.2 \pm 0.59$ & $3.2 \pm 0.70$ & $3.2 \pm 0.96$ \\
\hline Overall & $2.8 \pm 0.7$ & $2.8 \pm 0.64$ & $2.9 \pm 0.60$ & $3.06 \pm 0.59$ \\
\hline
\end{tabular}

\section{Discussion}

For the preparation of Idli, each batch 100-gram rice was soaked and change the proportion of fenugreek seed (T0:T1:T2:T3 is 5:10:15 and T0 is the control sample) the all these ingredient ground in a domestic mixture grinder and prepared in paste form. Fermentation required a minimum of 4 hours. Except for the control sample, added decorticated green gram dal and black gram dal, fenugreek seed and rice in changed proportion (these samples are T1, T2, and T3 respectively). In the present research study three sets of treatment samples as above but the following modification, were subjected to sensory evaluation.

In all the four samples organoleptic score of all the parameter viz. Colour, flavor, texture, appearance, and acceptability show at the approximately same score with the added fenugreek seed but the overall more acceptable sample in three incorporated samples was T3 sample. Admixture containing fenugreek seed with Moog shows a remarkably high score overall with a control sample it also confirmed by statistical analysis and evaluation of mean and standard error. The study was brings forth a highly significant conclusion that the present study 15 gram fenugreek seed Idli was more acceptable. Based on color sample A was attractive based on flavor and taste all the sample was the same. Based on texture sample $\mathrm{C}$ was more acceptable. Overall acceptability of four samples, sample A was more acceptable because it is controlled but in three variations of the sample, sample D was more acceptable.

\section{Summary and Conclusion}

The research study was an attempt to explore the possibility of preparing a gluten-free fermented product. The work was designed to produce gluten-free product preparing different samples of Idli by adding modified or so-called standardized fenugreek seeds and green gram dal in different proportion, preparing a product with the addition of two different types of dal and fenugreek seeds in different proportion and evaluation of sensory properties.

For studying the extent of replacement of the standardized fenugreek seed with green gram dal three different admixtures containing 5\%,10\%,15\% fenugreek seeds, and 10\%,15\%,20\% of green gram dal along with $100 \%$ of rice and $20 \%$ of urad dal. These were symbolized as T1, T2, and T3. And one controls T0 respectively. Based on the color sample A was attractive. Based on flavor and taste all the samples were the same along with added T0. Based on texture sample $\mathrm{C}$ was more acceptable. Overall acceptability of four samples, sample A was more acceptable because it is controlled but in three variations of the sample, sample D was more acceptable. Based on observation made in the present study following conclusion may be drawn-

1. Gluten-free product Idli standardized with fenugreek seeds and green gram dal is protein-rich. 
2. The admixture of $15 \%$ of fenugreek seeds and $20 \%$ green gram dal was more acceptable.

3. Approximately the same score in $\mathrm{T} 1$ and $\mathrm{T} 2$ samples in organoleptic evaluation.

4. Based on a significant difference without the addition of T0 all three samples are not different at the $1 \%$ level and a $5 \%$ level.

5. With the addition of the control sample there is a significant difference between all four samples at $1 \%$ level and 5\%level.

\section{References}

1. Gopalan C, Rama Sastri BV, Balasubramanian SC, Narasinga Rao BS, Deosthala YG, Pant KC. Nutritive Value of Indian Foods. Indian Council of Medical Research Publication, 1971, 60-114.

2. Nutrient content claims for good source, high, more, and high potency, Specific Requirements for Nutrient Content Claims. Food Labeling, Code of Federal Regulations, US Food and Drug Administration, 2017.

3. Bentley, Robert and Henry Trimen. Medicinal Plants; being descriptions with original figures of the principal plants employed in medicine and an account of the characters, properties, and uses of their parts and products of medicinal value. London, Churchill. WZ 295 B556m, 1880 .

4. Sumati R, Mudambi MV, Rajagopal. Fundamentals of Foods, Nutrition and Diet Therapy. New Age International (P) Ltd., Publishers, 2007, 375.

5. Balasubramanium $\mathrm{S}$, Singh $\mathrm{N}$, Ilys SM, Wanjari OD. Effect of selected decorticated legumes protein on rheology of maize extrudate pastes. J Food Sci. Technol. 2006; 43:590-594.

6. Desikachar HSR, Radhakrishnamurthy R, Rao GR, Kadol SB, Srinivasan M, Subramanyan V. Studies on idli fermenteation. J Sci Ind Res. 1962; 19C:168-172.

7. Rajalakshmi R, Nanavaty K, Gumastha A. J Nutr Diet India. 1964; 1:276.

8. Davidson S, Meiklejohn AP, Passmore R. Human nutrition and dietetics, 1963.

9. Aykroyd WR. Special Report ICMR. No. 42. $6^{\text {th }}$. New Delhi, 1963. 